\title{
Religiosidade e Espiritualidade no Processo de Luto de Pais cujos Filhos
}

\section{Morreram Crianças}

\author{
Cristine Gabrielle da Costa dos Reis* \\ Universidade Federal de Santa Catarina - UFSC, Florianópolis, SC, Brasil \\ ORCID: https://orcid.org/0000-0002-8935-4715 \\ Alberto Manuel Quintana** \\ Universidade Federal de Santa Maria - UFSM, Santa Maria, RS, Brasil \\ ORCID: https://orcid.org/0000-0001-7356-6142 \\ Fernanda Nardino*** \\ Universidade Federal de Santa Maria - UFSM, Santa Maria, RS, Brasil \\ ORCID: https://orcid.org/0000-0002-8453-3941
}

\begin{abstract}
RESUMO
Diante da complexidade dos fatores que envolvem a perda de um filho, o objetivo deste artigo foi compreender o papel da religiosidade e da espiritualidade no processo de luto de pais cujos filhos morreram crianças. Para tanto, foram realizadas 11 entrevistas com pais que haviam perdido os filhos crianças dentro de um intervalo de 4 meses a 1 ano e 4 meses. Os dados, coletados entre maio e outubro de 2015, foram analisados sob a perspectiva da análise de conteúdo temática. Os resultados mostraram que os pais atribuíram a causa da morte à vontade de Deus, o que permitiu conferir uma razão à perda. A partir da crença da vida após a morte, acreditaram que seus filhos poderiam estar vivos em outra dimensão, o que favoreceu o sentimento de esperança no reencontro. As relações com a fé variaram, de modo que alguns pais se direcionaram em busca da religiosidade, outros questionaram suas crenças prévias e outros se revoltaram contra Deus. Assim, destaca-se a necessidade de considerar os aspectos subjetivos em conjunto com as ferramentas que podem auxiliar na elaboração da perda, a fim de que haja um manejo adequado do luto parental.
\end{abstract}

Palavras-chave: morte, luto, espiritualidade, religião.

\section{Religiosity and Spirituality in the Process of Grief of Parents whose}

\section{Children have Died}

\begin{abstract}
Towards the complexity of factors involving the loss of a child, this article aimed to comprehend the role of religiosity and spirituality in the process of grief of parents whose children have died. Therefore, 11 interviews were conducted with parents who had lost their children in a range of 4 months to 1 year and 4 months. Data - which were collected from
\end{abstract}


May to October of 2015 - were analyzed from the perspective of the thematic content analysis. The results showed that parents would attribute the cause of death to God's will, which would give them a reason for the loss. Based on the belief of life after death, they would believe that their children could be alive in another dimension, which stimulated the hope for meeting again. The relationship with faith was varying so that some parents had driven into religiosity, while others had questioned their previous beliefs and others had risen against God. Thus, it is emphasized the necessity of considering subjective aspects with tools that might help in the elaboration of the loss, in order to promote an adequate handling of parental grief.

Keywords: death, bereavement, spirituality, religion.

\section{Religiosidad y Espiritualidad en el Proceso de Duelo de Padres cuyos Hijos}

\section{Murieron}

\section{RESUMEN}

Frente a la complejidad de los factores que implican perder un hijo, el objetivo del artículo fue comprender el papel de la religiosidad y la espiritualidad en el proceso de duelo de padres cuyos hijos murieron niños. Fueron realizadas 11 entrevistas con padres que habían perdido los hijos niños en un intervalo de 4 meses a 1 año y 4 meses. Los datos, recolectados entre mayo y octubre de 2015, fueron analizados desde la perspectiva del análisis de contenido temático. Los resultados mostraron que los padres atribuyeron la causa de la muerte a la voluntad de Dios, permitiendo dar una razón a la pérdida. Partiendo de la aceptación de la vida después de la muerte, creían que sus hijos podrían estar vivos en otra dimensión, favoreciendo el sentimiento de esperanza en el reencuentro. Las relaciones con la fe variaron, así que algunos padres se direccionaron en busca de la religiosidad, otros cuestionaron sus creencias previas y otros se rebelaron contra Dios. Así, se destaca la necesidad de considerar los aspectos subjetivos junto con las herramientas que puedan auxiliar en la elaboración de la pérdida para realizar un manejo adecuado del duelo parental.

Palabras clave: muerte, duelo, espiritualidad, religión.

A complexidade que envolve a morte pode estar relacionada ao fato de ela carregar consigo um conjunto de aspectos que a dirigem para a seara do incontrolável. Face a isso, muitas vezes a morte é considerada uma situação limítrofe e catastrófica que não pertence à vida cotidiana e que coloca o sujeito frente a sua fragilidade diante da falta de sentido que ela costuma acarretar (Quintana, 1999). Nessa direção, destaca-se o luto como um processo psíquico que, ao ser elaborado, permite a reconstrução simbólica do rompimento provocado por uma perda. Ademais, ele se constitui como um recurso psíquico que o sujeito tem para 
lidar com as questões da finitude, do trauma, da perda e da morte (Pinheiro, Quintella, \& Verzteman, 2010). O processo de luto se constitui como uma resposta normal à perda e costuma ser caracterizado por quadros clínicos que se mesclam e se substituem, englobando períodos de entorpecimento, saudade, procura pelo outro, desorganização e recuperação (Parkes, 1998). Desse modo, é um processo subjetivo de reconstrução simbólica, sendo dinâmico e variável em natureza, intensidade e duração (Franqueira, Magalhães, \& FéresCarneiro, 2015).

Além da sua constituição subjetiva, ferramentas externas podem vir na direção de auxiliar nesse processo de elaboração, tais como a religiosidade e a espiritualidade. Frente à impotência que a morte (ou mesmo sua possibilidade) remete, os indivíduos buscam certo controle sobre ela por meio de ritos que permitam a construção de novas representações simbólicas. É nesse sentido que os sujeitos podem buscar o auxílio do sagrado, pois a religiosidade permite a atribuição de significado às vivências que, em virtude de uma ruptura simbólica, não possuem uma explicação disponível na realidade (Quintana, 1999). Assim, o sagrado favorece a relação entre o sujeito e a finitude humana (Marchi, 2005).

Cabe mencionar que há uma vasta discussão acerca da diferença entre a religiosidade e espiritualidade. Uma revisão de literatura analisou as diferenciações entre estes conceitos, apontando que o primeiro representa a prática ou expressão das crenças, a qual pode estar relacionada a uma instituição religiosa. Já o segundo se refere a uma dimensão mais ampla, que é inerente a cada sujeito e que o coloca diante de questões existenciais e da busca de sentido destas, ou seja, transcende a Religião (Gomes, Farina, \& Dal Forno, 2014). Assim, ainda que se reconheça essa distinção entre os termos, eles serão utilizados como sinônimos no presente artigo, tendo em vista a possibilidade da aproximação no tratamento sobre o transcendental do mundo real, além do fato de que, nos relatos analisados, os termos estão atrelados e não são excludentes.

Neste segmento, estudos apontam para o auxílio da espiritualidade e da religiosidade no enfrentamento de situações adversas (Melo, Sampaio, Souza, \& Pinto, 2015) e durante o processo de significação no luto (Farinasso \& Labate, 2012; Feldman, Fischer, \& Gressis, 2016; Fornazari \& Ferreira, 2010; Franqueira et al., 2015; Morelli, Scorsolini-Comin, \& Santos, 2014). Uma revisão bibliográfica de metanálise, que buscou avaliar a correlação entre religiosidade, espiritualidade e qualidade de vida, indicou a existência de tal correlação, em especial no que tange ao enfrentamento de experiências difíceis (Melo et al., 2015). Bousso, Poles, Serafim e Miranda (2011) corroboram essa concepção em sua pesquisa a respeito da perspectiva dos familiares em relação à experiência da doença. As autoras citam que os 
familiares creditam a Deus ou a forças ocultas a causa da morte do ente querido, o que diminui o sentimento de responsabilidade relativo a essa perda. Dessa forma, reforçam o caráter da religiosidade como um elemento com um arcabouço de explicações que auxilia na atribuição de significado à doença e à morte, além de trazer benefícios relativos ao sentimento de esperança e ao suporte emocional e social.

Somado a isso, o estudo de Farinasso e Labate (2012) a respeito do luto, religiosidade e espiritualidade em viúvas idosas demonstrou que a fé em Deus e as crenças religiosas funcionaram como estímulo para a superação da perda, ao passo que Feldman et al. (2016) apontaram para níveis mais baixos de sofrimento na vivência do luto recente de pessoas que declararam ser religiosas. Nesse sentido, a religiosidade proporciona a concepção de que existe alguém superior, que deseja o melhor para essas pessoas e que controla o trajeto de suas vidas (Fornazari \& Ferreira, 2010). Ainda, a crença de vida após a morte, proposta por certas religiões, favorece a construção de significados diante da perda (Farinasso \& Labate, 2012; Freitas \& Michel, 2014). Por outro lado, essa crença também evidencia um movimento de renegação, ou seja, um movimento de defesa por parte do sujeito em rechaçar a realidade traumatizante (Roudinesco, 1998), a exemplo da morte do filho.

No que tange ao luto de pais, destaca-se que a morte de um filho tende a ser considerada uma perda irreparável e difícil de ser elaborada, que provoca dor intensa, culpa, perda de um modo de existir (Freitas \& Michel, 2014) e o sentimento de incompletude (Cremasco, Schinemann, \& Pimenta, 2015). Franqueira et al. (2015), em seu estudo sobre as mães que perderam filhos na fase adulta, destacam que a religião oferece uma rede de significados que impele o enlutado a produzir um sentido para a perda. Os autores apontam que todas as participantes do estudo realizado trouxeram, em seus discursos, a figura de Deus, e que Ele é representado como um ser superior e protetor que controla os eventos das suas vidas. Diante disso, a religiosidade é destacada como uma valiosa ferramenta para a elaboração do luto (Franqueira et al., 2015), aceitação da perda, bem como do lugar de enlutado (Morelli et al., 2014).

De outro ângulo, a pesquisa de Costa (2016), cujo objetivo foi compreender a fé católica e suas possíveis mobilizações dentro do processo psíquico de assimilação e elaboração do luto, constatou um processo de reconstrução da relação do enlutado com a sua fé, assim como mudanças relativas à concepção de Deus. Nessa direção, Bakker e Paris (2013), ao examinarem o impacto da natimortalidade e morte neonatal na religiosidade dos pais, apontaram que cerca de $37 \%$ dos pais descreveram se sentir com a fé abalada e com o sentimento de estarem perdidos, e $16 \%$ estavam se sentindo traídos e com as expectativas 
frustradas. Isso porque os pais acreditavam que seriam recompensados por sua fé ou que um ser superior protegeria seu filho, o que provocou sentimentos de raiva, insegurança e dúvidas em relação a suas crenças religiosas e espirituais. De acordo com Jueckstock (2018), o fato de Deus não salvar seus filhos faz com que alguns pais passem a acreditar em uma injustiça de cunho pessoal, passando a considerar esse Deus como um ser distante, não amoroso e culpado.

Diante dos aspectos trabalhados, que se tratam da falta de sentido provocada pela morte, especialmente no que se refere à morte de um filho; a elaboração do luto a fim de reconstruir simbolicamente a ruptura ocasionada pela perda; e o auxílio da religiosidade/espiritualidade nos processos de ressignificação, destaca-se a relevância de embasar cientificamente o manejo do luto, levando em consideração o entendimento sobre a relação dos pais com a fé. $\mathrm{O}$ reconhecimento dos aspectos relacionados à religiosidade e à espiritualidade pode contribuir para a compreensão do lugar que as crenças religiosas/espirituais ocupam na elaboração do luto dos pais. Além disso, os resultados deste estudo podem subsidiar uma prática adequada dos profissionais da saúde ao se depararem com o luto parental, na medida em que permitem cotejar os recursos que esses pais possuem para lidar com a perda, bem como fornecer elementos para as pessoas próximas dos pais enlutados. Com isso, o objetivo deste artigo foi compreender o papel da religiosidade e da espiritualidade no processo de luto de pais cujos filhos morreram crianças.

\section{Método}

O estudo trata de uma pesquisa de abordagem qualitativa, de caráter descritivo e exploratório, uma vez que se buscou explorar as questões existenciais envolvidas em determinado fenômeno (Turato, 2013), assim como as interpretações atribuídas a este pelos sujeitos da pesquisa (Minayo, 2014). Os participantes da pesquisa foram pais cujos filhos morreram na infância em decorrência de alguma doença. Como critério de inclusão, estipulou-se o tempo de 1 mês a 1 ano após a morte da criança, por compreender que o primeiro ano da perda conserva características similares. Os dados foram fornecidos pela Vigilância Epidemiológica - como as causas do óbito, a data de nascimento, o nome da criança, dos pais e endereço - e respeitaram esse intervalo de tempo estipulado. Os participantes foram buscados por meio das declarações de óbitos disponíveis no Sistema de Informação de Mortalidade (SIM). Com isso, o primeiro contato, na grande maioria dos casos, foi pessoal, quando os locais de moradia foram encontrados. Por conta do tempo que 
envolveu a busca pelos participantes, a entrevista ocorreu com pais cujo tempo de perda do filho variou de 4 meses a 1 ano e 4 meses.

A idade das crianças foi estabelecida conforme a Lei n. 8.069 (1990) que discorre sobre o Estatuto da Criança e do Adolescente (ECA) (Lei n. 8.069, 1990), que considera criança a pessoa de até 12 anos de idade incompletos. A idade dos filhos falecidos variou entre zero dia (considerando crianças que, por conta de alguma doença, nasceram mortas) a 12 anos. Referente a isso, salienta-se que a amplitude de idade se deu, especialmente, pela limitação do número de pais e pela dificuldade de encontrá-los, em decorrência de registros de endereços incompletos ou pela mudança dos participantes das moradias registradas.

Foram realizadas 11 entrevistas, momento em que se encerrou a coleta de dados devido à saturação dos dados. A saturação teórica se refere ao momento que as informações coletadas passam a se repetir e novas entrevistas não acrescentam dados significativos para o alcance e a discussão dos objetivos propostos no estudo (Turato, 2013). Da totalidade de entrevistas, cinco foram realizadas com ambos os pais. Nas demais, só houve participação das mães, por motivos diversos, dentre os quais temos: o pai não querer participar, delegar esse assunto para mãe, estar por muito tempo longe; a mãe não ter mais o contato do pai; ou o pai ter falecido. Dos participantes, situa-se que a Mãe 1, Mãe 4, Mãe 5, Mãe/Pai 6, Mãe/Pai 8 e Mãe 9 eram da religião evangélica; a Mãe/Pai 3 eram da religião umbanda; a Mãe/Pai 10 eram mórmons; a Mãe/Pai 11 eram católicos; a Mãe 2 e a Mãe 7 manifestaram não estar vinculadas a nenhuma religião.

As coletas de dados se realizaram por meio de entrevistas semiestruturadas e contaram com um roteiro constituído por tópicos (Minayo, 2014), tais como: o recebimento da notícia do adoecimento; o processo de tratamento e/ou hospitalização; os sentimentos frente à perda iminente; a rede de suporte com a qual contavam; os sentimentos que emergiram frente à morte do filho; e a vivência da ausência do filho. As entrevistas foram gravadas em áudio, com prévio consentimento dos entrevistados e, posteriormente, transcritas. Foi estipulado previamente ao início da coleta que o local onde as entrevistas seriam desenvolvidas poderia ser escolhido pelos participantes, conforme se sentissem melhor. Diante disso, das 11 entrevistas realizadas, nove foram feitas nas residências dos entrevistados; uma aconteceu no hospital, por facilitar o deslocamento da participante; e outra na Universidade, a pedido do casal. A coleta de dados se deu a partir de maio de 2015 e se encerrou em outubro do mesmo ano.

A análise dos dados foi realizada por meio da análise de conteúdo temática (Bardin, 2010), considerando os núcleos de sentido da comunicação, segundo as etapas de: a) pré- 
análise, b) exploração do material e c) tratamento dos resultados obtidos e interpretação (Minayo, 2014). Nesse sentido, as entrevistas foram lidas e relidas pela pesquisadora e outros três colaboradores, buscando conteúdos que se repetissem ou tivessem caráter de relevância, ampliando a discussão, posteriormente, com outros dois pesquisadores com experiência na temática. Por meio disso, constituíram-se as categorias e subcategorias, segundo o critério de repetição, o qual preconiza que se coloquem em destaque os pontos reincidentes e o de relevância, ao uma fala ser considerada significativa, sob a ótica dos pesquisadores, tendo em vista o objetivo proposto (Turato, 2013).

O presente estudo foi aprovado pelo Comitê de Ética em Pesquisa da UFSM, sob o número 52750016.6.0000.5346. Esteve em consonância com a Resolução n. 466 (2012) do Conselho Nacional de Saúde, que orienta a ética em pesquisas com seres humanos. Ressaltase que, em conformidade com os preceitos éticos, a pesquisa previa o encaminhamento ao atendimento psicológico dos participantes que demostrassem aspectos que apontassem para um processo de luto comprometido ou que, por meio da entrevista, ficassem significativamente mobilizados. Diante disso, a Mãe1 e Mãe2 foram encaminhadas para atendimento, a primeira a pedido dela e a segunda com base na percepção da pesquisadora. Ademais, destaca-se que a identidade dos pais foi preservada, bem como a dos filhos. Assim, seus nomes foram trocados por Mãe ou Pai seguido de enumeração.

\section{Resultados e Discussão}

Em relação à religiosidade/espiritualidade dos pais mencionados neste estudo, visualiza-se um predomínio da religião evangélica (8 participantes), seguido pela religião católica ( 2 participantes), mórmon (2 participantes), umbanda (2 participantes). Além disso, situa-se a manifestação de não estar vinculado a nenhuma religião (2 participantes).

Destaca-se isso, uma vez que a religiosidade sustentou muitos movimentos dos pais diante da morte dos filhos, a qual foi entendida como veementemente contraditória. Há também questões que surgem frente à perda, tais como: "Por que foi assim? Por que comigo?". Nesse momento, o sujeito se depara com o real e com a ausência de sentido, aspectos que o impulsionam a procurar algo que lhe traga explicações que possam reconstituir seu universo simbólico (Quintana, 1999). Nessa direção, a religiosidade e a espiritualidade são elementos capazes de auxiliar, uma vez que: 
[...] o sagrado não precisa de regras e sua compreensão não necessita de racionalidades. E se a tecnologia facilita a vida material, a física explica as reações da matéria, a matemática calcula as dimensões e os espaços do universo, a filosofia se encarrega de matar os deuses, o sagrado permanece como possibilidade de diminuir o peso da transcendência [...], facilita a relação com a finitude da existência humana (Marchi, 2005, p. 53).

A religiosidade oferece um conjunto pronto de significações para o sujeito, que permite que o vazio que a morte traz seja ressignificado por meio de rituais, os quais facilitam a criação de novos arcabouços simbólicos (Quintana, 1999). Por conseguinte, entende-se que as crenças espirituais e/ou religiosas podem exercer a função de conceder um sentido à perda. No processo de enfrentamento da morte no contexto familiar, tais crenças, imersas na conjuntura sociocultural, tendem a auxiliar na significação da perda e podem representar, para os membros familiares, o crescimento e a aproximação da família, além de proporcionar maior controle interno (Bousso et al., 2011).

No contexto das considerações supramencionadas, pontua-se que, a partir dos resultados obtidos, formaram-se três categorias temáticas, as quais serão apresentadas a seguir. São elas: "Vontade de Deus"; “A morte: o início de outra vida" e "Relações com a fé”.

\section{Vontade de Deus}

A concepção de que a morte do filho aconteceu por algum plano maior, mesmo que esse plano não seja reconhecido pelos pais, pode trazer conforto ao sugerir a ideia de que a morte aconteceu por alguma razão (Bakker \& Paris, 2013). Nesse contexto, a religiosidade/espiritualidade se constitui como fonte de explicações, que ultrapassam aquelas de caráter mundano, para a perda prematura (Morelli et al., 2014). Segundo Quintana (1999), os processos mágico-religiosos podem ser usados como modo de minimizar o caos e a impotência diante dos eventos que chocam a rede simbólica de significados do sujeito. As explicações religiosas são evidentes no discurso dos entrevistados, como é exemplificado na fala que segue, pois a morte do filho, segundo a concepção da mãe, foi no tempo que Deus quis: "Mas era isso, a gente sempre acreditou na vontade de Deus. Que fosse o tempo que Deus quisesse dele aqui na terra." (Mãe 4).

Diante disso, a morte passa a se dar pela vontade de Deus - ou de forças ocultas-, o que demonstra, ao sujeito enlutado, que o controle dos acontecimentos é de um ser soberano 
que, por sua vez, sabe o que é melhor para essas pessoas (Bousso et al., 2011; Fornazari \& Ferreira, 2010). Além disso, a fé em Deus - considerado um ser divino e superior, independente da religião professada - parece ser utilizada como um recurso para manejar a dor do luto e preencher as brechas no universo simbólico que são abertas com a perda, uma vez que esse Deus costuma possuir características de um ser cuidador e protetor (Franqueira et al., 2015; Farinasso \& Labate, 2012). Em consonância com a literatura apontada, fica visível, nas seguintes falas, a entrega da situação nas mãos de Deus e a concepção de que foi Ele quem teve o controle sobre os eventos: "E a única coisa que eu fiz foi me entregar, entreguei tanto a minha vida, quanto a do nenê nas mãos de Deus, que Deus fizesse o melhor [...]" (Mãe 9).

É o que eu digo, tudo é ordem de Deus, quando é hora de Deus não adianta, fazer o que, se Deus quis assim [...] Não é fácil... as coisas acontecem tudo da forma melhor... Deus quer sempre o melhor pra gente, então, como ele era uma criança que não tinha maldade [...] Deus recolheu ele antes pra não deixar ele ficar sofrendo [...] (Mãe 6)

Na fala da Mãe 6 fica clara a compreensão de que foi Deus quem quis que acontecesse assim. Há uma explicação para o filho ter morrido, que é a vontade de Deus, contra a qual não tem o que ser feito: “fazer o quê?". Essa vontade é inquestionável, como se pode observar em outro relato: "[...] o Senhor sabe, a gente não vai questionar Deus. Claro que a gente sente, sentiu, mas a gente em momento algum ia... se era assim, era a vontade dele." (Mãe 10). O movimento de conceder a Deus a decisão relativa à morte para alívio do sofrimento do filho diminui o peso do sentimento de responsabilidade sobre essa morte, o que pode facilitar sua aceitação (Farinasso \& Labate, 2012). Por isso, compreende-se que o auxílio da religiosidade/espiritualidade para a diminuição do sentimento de responsabilidade e culpa diante da morte favorece que o enlutado desenvolva recursos para dar melhor encaminhamento ao luto.

O estudo de Franqueira et al. (2015) ressalta que foi possível identificar que até mesmo uma mãe que não aceita a morte do filho e possui sentimentos de raiva e revolta acredita na vontade de Deus e confia em sua decisão. Consoante ao que os autores encontraram em seus resultados, foi possível verificar, por meio da fala abaixo, que a mãe deixa claro tais sentimentos de revolta e incompreensão; apesar disso, não deixa de referenciar Deus como um ser em que ela deposita sua confiança: 
Eu digo assim, a minha fé não tá baseada no meu sentimento. O meu sentimento é de dor. Talvez de revolta. Mas a minha fé tá no que diz a palavra. [...] Meu questionamento é até com Deus, eu digo [...] Senhor, eu aceito, mas eu não entendo. E realmente a gente não entende. Mas o que a gente crê é que todas as coisas acontecem conforme a vontade de Deus, então a gente deposita toda confiança e tudo nas mãos de Deus. (Mãe 8)

Os trechos da fala "eu aceito, mas eu não entendo" e "meu questionamento é com Deus" deixam em evidência a incompreensão da mãe, ainda que ela esteja apegada a explicações religiosas. Assim, a partir da análise da fala, observa-se que, mesmo em pessoas que consideram a morte injusta, sem poder integrar o acontecimento em um contexto inteligível, a religiosidade permite a aceitação de tal fato, como se evidencia em: "Senhor, eu aceito, mas não entendo".

Além disso, Bousso et al. (2011) citam que as explicações encontradas pela família na religiosidade podem se dar na direção de que a experiência vivida trouxe efeitos positivos, como o crescimento, a regeneração ou a ajuda a outras pessoas. Essa última possibilidade pode ser verificada na fala do Pai 8: "Então, eu digo assim... a fé que a gente tem, que foi a principal coisa [...] E a gente usa isso pra ajudar outras pessoas também”. Para a Mãe 9, há um propósito para estar passando por isso:

Eu acho que Deus sempre tem um propósito, né, com as coisas que acontecem e se aconteceu foi permissão dele [...] eu creio que Deus me permitiu que eu passasse por essas dificuldades, essas lutas, porque alguma coisa ele queria comigo lá dentro. (Mãe 9)

Nesse sentido, observa-se a concepção que Deus teria um propósito para as perdas, o que as torna menos angustiantes, pois deixam de estar vazias e passam a ganhar uma razão. Com isso, a religiosidade se configura como um elemento organizador do luto ao trazer, em seu escopo, uma rede de significação que permite a atribuição de um sentido para a perda, o que pode contribuir para diminuir a intensidade do pesar (Franqueira et al., 2015). Cabe mencionar, ainda, que a análise realizada por Melo et al. (2015) acerca dos materiais que se relacionavam a doenças crônicas e morte considerou a espiritualidade e religiosidade como benéficas para a saúde dos sujeitos envolvidos, de modo que, ao auxiliarem na elaboração do luto, consequentemente, apontam para melhora na qualidade de vida (Melo et al., 2015). 
Diante disso, entende-se que a religiosidade/espiritualidade atua entrelaçando o acontecimento inexplicável, que é a perda de um filho, às explicações da ordem religiosa ou transcendentais, capazes de preencher um evento esvaziado de sentido. A possibilidade de articulação entre uma experiência psíquica dolorosa, até então desprovida de significado, com algum elemento espiritual/religioso que ofereça uma explicação que possa ultrapassar o caráter puramente científico ou racional da morte - como a vontade de Deus, enquanto um ser superior- é capaz de oferecer sentido e conforto aos enlutados, facilitando a elaboração do luto.

\section{A morte: o início de outra vida}

Nesta categoria, os pais expressaram a crença de que os filhos foram para outro lugar após a morte e demonstraram a esperança em reencontrá-los. Tal crença se configurou como algo reconfortante, que trouxe consolo frente à perda e favoreceu o processo de aceitação.

Tendo isso em vista, destaca-se que, de maneira geral, as religiões tratam o evento da morte como uma transição para um lugar melhor, o que favorece que o enlutado construa significados positivos acerca da perda (Farinasso \& Labate, 2012). Bousso et al. (2011) destacam, nos discursos analisados em seu estudo, a concepção de que a vida não termina com a morte. Nesse sentido, tem-se que as religiões oferecem a crença da vida após a morte e a ideia de que, futuramente, os entes queridos poderão se reencontrar.

Concernente a esse aspecto, no recorte da fala da Mãe 10, é possível verificar que a religião do casal prega que um dia eles estarão com sua filha e irão criá-la. Nesse contexto, é como se ela não tivesse, de fato, morrido, mas como se ela estivesse vivendo em outro plano: "E na nossa religião a gente tem que é pra eternidade, então um dia a gente vai criar ela." (Mãe 10). A ideia de reencontro também esteve presente no discurso do Pai 8: "Então, eu digo assim... a fé que a gente tem, que foi a principal coisa. A esperança muito importante também. Esperança que um dia vai se reencontrar." (Pai 8).

Percebe-se que os pais embasam em suas crenças religiosas a expectativa de um reencontro futuro com os filhos, mesmo tendo religiões diferentes. Essa esperança permite que a dor da perda seja abrandada e que haja a possibilidade da ressignificação da relação com o filho morto. Diante disso, a espiritualidade se constitui como um meio para encontrar sentido para essa perda e permite que se nutra a crença de que os filhos vivem em um lugar melhor, realizando a manutenção da relação que foi rompida na dimensão corporal (Freitas \& Michel, 2014). Uma vez que o luto se constitui como trabalho de ligação e integração daquilo 
que fica sem narrativa por um momento, mediante a construção de sentidos para a dor psíquica (Pinheiro et al., 2010), reitera-se que, à medida que a religiosidade/espiritualidade possibilita a articulação de tais sentidos, ela está na direção de auxiliar o trabalho psíquico do luto.

Nesse viés, Feldman et al. (2016) indicaram que a crença na vida após a morte foi associada a um melhor encaminhamento relacionado ao luto. Para os pais do estudo de Bakker e Paris (2013), a noção de vida após a morte remeteu à continuidade da existência do bebê, o que também evocou a preocupação com o bem-estar do filho onde ele estivesse. $\mathrm{Na}$ fala da Mãe 3, que se declarou umbandista, é possível visualizar a relação que ela estabeleceu entre o seu sofrimento e o "descanso" do filho:

Na minha lei eu penso assim, se eu não ajudar meu filho a evoluir, ele vai ficar aqui sofrendo. Se eu me encarnar nele de uma forma que qualquer mãe se encarna [...] eu não ia ajudar ele [...]. Quando a gente tem muita coisa no coração eles demoram pra descansar [...] (Mãe 3)

A narrativa da Mãe 3 está situada em conformidade aos preceitos da sua religião, evidenciados pela crença de que é necessário, para a evolução espiritual do filho, que a mãe não se encarne nele. Nota-se, ainda, a relação que ela estabelece das "coisas no coração" com o descanso do filho, fazendo uma equivalência entre aquilo que é sentido pela mãe e a possibilidade de o filho estar bem. Observa-se, nesta relação, a ligação e, de certa maneira, a influência daquilo que é realizado pelas mães e o bem-estar dos filhos. A religião da mãe, a qual ela chama de lei, diz que é sua responsabilidade ajudar o filho. Frente a isso, reflete-se que, por um lado, a religiosidade funciona como um elemento utilizado para diminuir o sofrimento da perda, mas, por outro, é possível pensar na responsabilização destinada aos pais pelo bem-estar dos filhos, mesmo após sua morte. Nesse sentido, se o filho não pode descansar, isso, por sua vez, pode estar relacionado à falta de engajamento dos pais.

Além disso, acredita-se que a crença na vida após a morte revela um mecanismo de renegação que a religião promove: se ele está no céu com Deus e se eles vão se reencontrar, o filho não morreu completamente. Existe o reconhecimento da morte; mas, ao mesmo tempo, permanece a crença em um futuro reencontro, o que revela um duplo movimento: o reconhecimento da perda e, simultaneamente, a dissociação desta. A renegação remete a um mecanismo psíquico de recusa de uma realidade percebida como negativa, em que há a coexistência de duas vertentes contraditórias da realidade: o reconhecimento e a recusa 
(Roudinesco, 1998). Assim, depreende-se que esse movimento promovido pela crença após a morte, quando aliado a uma estrutura psíquica que, em vez de bloquear, auxilia na elaboração do luto, não parece prejudicar a reconstrução simbólica da perda, tendo em vista que traz um alento para a brecha que a morte do filho provoca ao indicar que ele está melhor em outro lugar.

Nesse sentido, compreende-se que a crença na continuidade da vida após a morte oferece a possibilidade de manter a relação com o filho que morreu, fazendo com que a morte, seja, gradualmente, ressignificada, além de permitir a manutenção da esperança diante da vivência do luto. Por outro lado, sinaliza-se que essa crença pode funcionar como um meio da renegação da realidade da morte, dificultando, nesse caso, que o enlutado entre em contato com a perda. Marca-se, frente a isso, que o uso e a apropriação da religiosidade/espiritualidade - como ferramenta externa - depende também da subjetividade e dos recursos prévios que o sujeito possui, os quais podem determinar de que maneira ela se encaixa na elaboração psíquica.

\section{As relações com a fé}

Reitera-se que crenças e valores religiosos são buscados para conceder um significado e um sentido à morte, proporcionando uma diminuição da angústia, o que pode facilitar o entendimento dessa perda (Bousso et al., 2011). Nessa direção, observa-se que o amparo na religião, por vezes, não é algo inerente. Ele é buscado, como exemplifica a fala abaixo:

E... quando a gente fica com aquela... e pede pra Deus e pede pra Santa, pede pra esse, faz oração [...] Na realidade tu entra num desespero que se bobear tu pede ajuda pra uma galinha preta na rua. Não tem... tu te apavora. Porque é uma coisa que não tá sob teu poder. (Pai 11)

O pai parece ter clareza de que a religiosidade/espiritualidade é buscada, pois, por mais que ele peça ajuda a Deus, ele diz que isso se dá em virtude do desespero. Fica evidente quando ele compara esse Deus ou os santos com a galinha preta. Tal reconhecimento não parece, no entanto, ser comum nos pais. Diante disso, é possível sinalizar diferentes movimentos em relação à busca de sentido na religiosidade, uma vez que alguns pais já eram religiosos antes da morte do filho e outros se apoiaram na religião após essa morte, com a finalidade de procurarem um amparo no momento de perda que estavam vivenciando. 
Coadunado a isso, o estudo de Bakker e Paris (2013) traz a experiência de pais que não eram religiosos e se mostraram interessados em desenvolver uma relação com a religião ou espiritualidade após sua perda. Nessa direção, também fica em evidência que a religiosidade é convocada frente à falta de controle, o que corrobora com as discussões já mencionadas (Fornazari \& Ferreira, 2010; Quintana, 1999).

Na narrativa da Mãe 1, ela relata sobre uma mulher que conheceu no hospital e que perdeu a filha. Segundo seu relato, essa mulher acreditava fortemente na vontade de Deus a ponto de aceitar o evento da morte. Percebe-se que há um desejo, por parte da Mãe 1, em ser tão religiosa quanto ela, como se, ao ter a mesma fé, pudesse aceitar a perda da mesma maneira:

[...] mas ela tem uma fé enorme essa mulher. Eu queria ter a fé dela, sabe, porque ela se agarrou de um jeito... Ela aceita. E eu já não aceito muito. Agora que eu to começando, assim, a querer aceitar... mas ela aceita. Ela disse que foi a vontade de Deus e... se apega. Eu de início eu não aceitava, não adianta tu vir pra mim assim 'ai aceita', eu não aceitava. Ela não... faz uns 3 meses já que eu conversei com ela, ela aceita aquilo ali, sabe, eu não... agora que eu to querendo aceitar um pouquinho. (Mãe 1)

Ao pensar que a vivência de uma crença e a fidelidade a Deus é uma forma de ter controle sobre o imponderável, Marchi (2005) aponta que a experiência religiosa supõe que há um comprometimento dos dois lados. Por um lado, o sujeito age com devoção, obediência, entre outras atuações. Do outro lado, o lado do santo (ou de Deus), há a proteção, a salvação, o cuidado. Dessa maneira, com a morte do filho, o sujeito pode entender que não há reciprocidade da parte de Deus, como evidencia a Mãe 2: “[...] eu tava com esperança. Eu rezava, eu fiz promessa. Ela faleceu... até a mãe ficou braba comigo porque eu disse assim "então Deus não existe, porque, né... vai tirar um filho de uma mãe"”.

Nesse sentido, pode haver a reação de revolta contra Deus e sentimentos de incompreensão do porquê algo tão doloroso quanto à perda de um filho foi acometer as mães (Cremasco et al., 2015). Em outras palavras, os pais se perguntam: como Deus, em sua onipotência, não é capaz de impedir uma morte considerada precoce? (Costa, 2016). O mesmo é ilustrado no trecho anunciado pela Mãe 2: 
[...] eu fiquei meio descrente. Uma hora eu tenho fé, outra hora não, fiquei meio confusa. Deus existe, Deus não existe... já nem sei mais. E se Deus existe, por que ele deixa tantas pessoas boas passar trabalho, né? Se Deus faz milagre, por que não fez um milagre? (Mãe 2)

Diante disso, sinaliza-se que a Mãe 2 evidenciou que se mostrava descrente após a morte da filha. Há, nesse contexto, um movimento contrário daqueles pais que se direcionam em busca da religiosidade/espiritualidade. Isso pode ser pensado com base em que, frente à perda, as expectativas em relação à segurança, ao controle e à justiça podem ser frustradas, de modo a levar os pais a questionarem suas tradições religiosas, considerando-as inconsistentes (Bakker \& Paris, 2013). Brigar com o destino ou com Deus é uma forma de tentar recuperar o controle ou encontrar alguma explicação para a morte, a fim de que o sujeito não se sinta impotente (Parkes, 1998). Nesse sentido, acredita-se que, mesmo que se sintam traídos e com a fé abalada, os pais enlutados estão atribuindo sentido ao que aconteceu ao encontrar um culpado para isso, ou seja: "Deus, que deveria proteger não o fez".

Nessa perspectiva, um estudo desenvolvido com pais que perderam um filho criança, cujo objetivo era examinar as experiências de pesar dos participantes através da espiritualidade relacional, apontou para vivências de luto mais difíceis, a longo prazo, para aqueles participantes que responsabilizavam Deus pela morte dos seus filhos (Jueckstock, 2018). Na mesma direção, os resultados da pesquisa de Feldman et al. (2016) associaram as visões negativas em relação a Deus com luto mais intenso e níveis mais baixos de aceitação. Cabe mencionar que, indo ao encontro dos resultados dos estudos citados, na presente pesquisa, a mãe que apresentou maior revolta em relação a Deus era a que indicava, em seus relatos, maiores dificuldades de aceitação e encaminhamento do luto.

Ainda, por vezes, as respostas sobre a morte do filho parecem inacessíveis, uma vez que só Deus as possui: "E a minha mãe diz: 'minha filha, tu vai morrer e tu não vai achar a tua resposta [...] tu não vai entender o porquê, porque só Deus sabe, não é tu'” (Mãe 1). Nessa direção, os participantes do estudo de Bakker e Paris (2013) também cobravam respostas de Deus, alguns de maneira incisiva, o que deixa transparecer que era uma explicação que só Ele poderia dar.

Além disso, a experiência da perda pode promover mudanças nas crenças e nas práticas de fé, de modo que os pais podem ressignificar sua relação com a religiosidade e transcendência, muitos no sentido de um processo positivo, ou seja, um relacionamento mais 
estável, com menos raiva e menos dúvidas (Bakker \& Paris, 2013). Diferentemente, é possível observar, no diálogo dos pais, outra vinculação com a religiosidade:

Mãe 11: Eu sempre rezei muito, [...] sempre tive muita fé. E depois do que aconteceu com o [filho], não é que eu não tenha mais fé... eu rezo menos do que antes. [...] Eu ainda tenho fé, eu acredito em Deus [...] mas não tenho aquele...

Pai 11: Entusiasmo

Mãe 11: Exato. Parece que ficou meio...

Pai 11: Tipo ficou me devendo

Mãe 11: [...] não é no sentido de 'tá me devendo'. Tá me devendo sim uma explicação [...] do porquê tu me levou o meu filho. Isso tu fica te perguntando todos os dias: por que, por que... Mas não que assim 'ah não acredito mais em Deus porque levou meu filho'. [...] Se não eu vou tá brigando com ele, né [...]

Para o pai, o entusiasmo diminuiu, além de ainda haver um sentimento de que Deus ficou devendo uma explicação para ele, ou seja: haveria um motivo para a morte, mas a explicação ainda não foi dada a ele. Da mesma forma, para a mãe, Deus está devendo uma explicação para a morte do filho, o que indica que essa explicação existe, mas que ela ainda não recebeu. Essa outra relação com a religiosidade também encontra correspondência com o movimento que esta mãe (Mãe 11) mencionou ter feito, ao buscar leituras relativas ao espiritismo. Ou seja, a procura por outras crenças, para além daquelas embasadas na religião com a qual estava vinculada, que possam sustentar explicações outras sobre a morte. Além disso, transparece em sua fala certo receio de brigar com Deus. O diálogo sugere que a vivência do luto propõe um olhar diferenciado para sua fé, havendo mudanças, dúvidas, questionamentos, frustrações, sensação de vulnerabilidade e sentimento de menor proteção. Essa experiência pode colocar uma nova lente, de modo que a relação com a fé seja ressignificada (Costa, 2016). Dessa maneira, é inferível que, diante da perda, é possível que os pais desenvolvam diferentes relações com a fé, desde apego a uma religião ou crenças espirituais, até revolta contra Deus ou questionamento de suas crenças.

\section{Considerações Finais}

Diante do exposto, em consonância com o objetivo proposto, qual seja, compreender o papel da religiosidade e da espiritualidade no processo de luto de pais cujos filhos morreram 
crianças, entende-se que a religiosidade promove sentimentos de esperança de reencontro, possibilidade de atribuição de sentido e alívio da responsabilidade, sendo uma alternativa à ruptura da relação existente no plano real. Nesse contexto, a religiosidade/espiritualidade pode ser usada como amparo, auxílio, constituindo-se como um elemento que favorece a significação da perda. Destaca-se que, mesmo os participantes tendo religiões diversas, não foram identificados resultados divergentes quanto à significação da perda e papel destas no processo do luto parental.

Por outro lado, sinaliza-se o movimento de renegação da perda, o qual, mesmo que implícito, apresenta-se em frases como "morreu para a vida eterna", "vamos nos encontrar", "ele está te cuidando lá de cima". Tais frases são propagadas comumente por algumas religiões e evocam essa dupla crença: o filho teria morrido, mas, mesmo assim, continua vivendo de uma outra maneira. Ou seja: ele está vivo em outro lugar, o que pode se constituir como um meio de não entrar em contato com a morte de fato. Diante disso, é preciso destacar a estrutura subjetiva de cada um: o modo como cada sujeito faz uso dessas crenças também diz sobre seus próprios mecanismos psíquicos, uma vez que tais crenças podem auxiliar na elaboração do luto ou funcionar como um elemento para os enlutados evitarem esse processo.

Em relação às limitações do presente estudo, assinala-se a amplitude de idade das crianças que morreram, o que inviabilizou a formação de um grupo mais homogêneo no que tange à faixa etária. Outra limitação trata da dificuldade de encontrar os pais, em virtude das mudanças de endereços não notificadas ou de endereços incompletos. Assim, sugere-se que novas pesquisas possam ser desenvolvidas a partir da delimitação de uma faixa etária da criança, a fim de compreender as diferentes variáveis que podem influenciar na vivência do luto parental. Ademais, é possível que futuras pesquisas, que tenham como objetivo identificar as nuances no processo de luto, causadas a partir das diferentes religiões, possam contribuir de uma maneira mais específica sobre a articulação que os enlutados fazem com a religiosidade/espiritualidade para a elaboração da perda, haja vista a lacuna na produção científica sobre materiais que abordem tal diferenciação no processo de luto.

Quanto às contribuições do estudo, salientam-se os aspectos discorridos acerca do papel da religiosidade e da espiritualidade como recursos que podem auxiliar na elaboração do luto, os quais podem ser tomados como possíveis mediadores da vivência da perda. Com isso, espera-se fornecer subsídios para a intervenção dos profissionais da saúde no sentido de que esses elementos sejam reconhecidos e valorizados, uma vez que influenciam o processo de luto dos pais. Nessa lógica, pontua-se a necessidade de uma escuta atenta por parte desses profissionais, a fim de compreender se esses recursos estão sendo utilizados para enfrentar a 
perda e elaborar o luto ou se estão sendo mobilizadas como artifício para evitar que se entre em contato com essa perda.

Reitera-se, ainda, a relevância da presente pesquisa, uma vez que dá luz à perspectiva que envolve as crenças religiosas e espirituais e suas relações com a experiência da perda e com a estrutura psíquica prévia do sujeito. Acrescenta-se, por fim, o fato de a pesquisa ter sido desenvolvida com ambos os pais, o que amplia o olhar sobre o fenômeno do luto e contribui com outros estudos já publicados, nos quais predominam a perspectiva das mães.

\section{Referências}

Bardin, L. (2010). Análise de conteúdo. Lisboa: Edições 70.

Bakker, J. K., \& Paris, J. (2013). Bereavement and Religion Online: Stillbirth, Neonatal Loss, and Parental Religiosity. Journal for the Scientific Study of Religion, 52(4), 657-674. doi: 10.1111/jssr.12066

Bousso, R. S., Poles, K., Serafim, T. S., \& Miranda, M. G. (2011). Crenças religiosas, doença e morte: Perspectiva da família na experiência de doença. Revista da Escola de Enfermagem da USP, 45(2), 397-403. doi: 10.1590/S0080-62342011000200014

Brasil (1990). Lei n. 8.069, de 13 de julho de 1990. Dispõe sobre o Estatuto da Criança e do Adolescente e dá outras providências. Brasília, DF: Presidência da República. Recuperado de http://www.planalto.gov.br/ccivil_03/leis/18069.htm

Brasil (2012). Resolução n. 466, de 12 de dezembro de 2012. Diretrizes e normas regulamentadas de pesquisas envolvendo seres humanos. Brasília, DF: Ministério de Saúde/Conselho Nacional de Saúde. Recuperado de http://conselho.saude.gov.br/resolucoes/2012/Reso466.pdf

Costa, A. P. R. (2016). A reconstrução da fé no enfrentamento do luto: Teologia e psicologia em diálogo. (Dissertação de Mestrado). Pontifícia Universidade Católica do Rio Grande do Sul, Porto Alegre, RS, Brasil. Recuperado de http://tede2.pucrs.br/tede2/handle/tede/5891

Cremasco, M. V. F., Schinemann, D., \& Pimenta, S. O. (2015). Mães que Perderam Filhos: Uma Leitura Psicanalítica do Filme Rabbit Hole. Psicologia: Ciência e profissão, 35(1), 54-68. doi: 10.1590/1982-3703002152013

Farinasso, A. L. C., \& Labate, R. C. (2012). Luto, religiosidade e espiritualidade: Um estudo clínico-qualitativo com viúvas idosas. Revista Eletrônica de Enfermagem, 14(3), 58895. doi: 10.5216/ree.v14i3.14453 
Feldman, D. B., Fischer, I. C., \& Gressis, R. A. (2016). Does Religious Belief Matter for Grief and Death Anxiety? Experimental Philosophy Meets Psychology of Religion. Journal for the Scientific Study of Religion, 55(3), 531-539. doi: 10.1111/jssr.12288

Fornazari, S. A., \& Ferreira, R. E. R. (2010). Religiosidade/espiritualidade em pacientes oncológicos: Qualidade de vida e saúde. Psicologia: Teoria e Pesquisa, 26(2), 265272. doi: 10.1590/S0102-37722010000200008

Franqueira, A. M. R., Magalhães, A. S., \& Féres-Carneiro, T. (2015). O luto pelo filho adulto sob a ótica das mães. Estudos de Psicologia, 32(3), 487-497. doi: 10.1590/0103$166 X 2015000300013$

Freitas, J. L., \& Michel, L. H. F. (2014). A maior dor do mundo: O luto materno em uma perspectiva fenomenológica. Psicologia em Estudo, 19(2), 273-283. doi: 10.1590/1413737222324010

Gomes, N. S., Farina, M., \& Dal Forno, C. (2014). Espiritualidade, Religiosidade e Religião: Reflexão de conceitos em artigo psicológicos. Revista de Psicologia da IMED, 6(2), 107112. doi: 10.18256/2175-5027/psico-imed.v6n2p107-112

Jueckstock, J. A. (2018). Relational Spirituality and Grief: A Qualitative Analysis of Bereaved Parents. Journal of Psychology and Theology, 46(1) 38-51. doi: $10.1177 / 0091647117753902$

Marchi, E. (2005). O sagrado e a religiosidade: vivências e mutualidades. História: Questões \& Debates, 43(2), 33-53. doi: 10.5380/his.v43i0.7861

Melo, C. F., Sampaio, I. S., Souza, D. L. A., \& Pinto, N. S. (2015). Correlação entre religiosidade, espiritualidade e qualidade de vida: Uma revisão de literatura. Estudos $e$ Pesquisas em Psicologia, 15(2), 447-464. Recuperado de http://pepsic.bvsalud.org/scielo.php?script=sci_arttext\&pid=S1808$42812015000200002 \& \operatorname{lng}=\mathrm{pt} \& \operatorname{lng}=\mathrm{pt}$

Minayo, M. C. S. (2014). O desafio do conhecimento: Pesquisa qualitativa em saúde (12.ed.). São Paulo: Hucitec.

Morelli, A. B., Scorsolini-Comin, F., \& Santos, M. A. (2014). Elementos para uma intervenção em aconselhamento psicológico com pais enlutados. Psico, 45(4), 434-444. doi: 10.15448/1980-8623.2014.4.14640

Parkes, C. M. (1998). Luto: Estudos sobre a perda na vida adulta. (M. H. Franco, Trad.). São Paulo: Summus. 
Pinheiro, M. T. S., Quintella, R. R., \& Verztman. (2010). Distinção Teórico-Clínica entre depressão, luto e melancolia. Psicologia Clínica, 22(2), 147-168. doi: 10.1590/S010356652010000200010

Quintana, A. M. (1999). A ciência da benzedura. São Paulo, SP: EDUSC.

Roudinesco, E. (1998). Dicionário de Psicanálise. Rio de Janeiro: Jorge Zahar.

Turato, E. R. (2013). Tratado da metodologia da pesquisa clínico-qualitativa: Construção teórico-epistemológica discussão comparada e aplicação nas áreas da saúde e humanas (6a ed.). Petrópolis, RJ: Vozes.

\section{Endereço para correspondência}

\section{Cristine Gabrielle da Costa dos Reis}

Rua Deputado Antônio Edu Vieira, 320, Florianópolis - SC, Brasil. CEP 88040-001

Endereço eletrônico: cristinecostareis@ hotmail.com

\section{Alberto Manuel Quintana}

Rua Tiradentes, 23 apto 701, Santa Maria - RS, Brasil. CEP 97050-730

Endereço eletrônico: albertom.quintana@gmail.com

\section{Fernanda Nardino}

Avenida Presidente Vargas, 1880 apto 303, Santa Maria - RS, Brasil. CEP $97015-512$

Endereço eletrônico: fernanda.nardino@hotmail.com

Recebido em: 16/08/2019

Reformulado em: 24/07/2020

Aceito em: 25/07/2020

\section{Notas}

* Psicóloga e Mestre pela Universidade Federal de Santa Maria (UFSM). Doutoranda do Programa de Pósgraduação em Psicologia da UFSC. Bolsista CAPES.

** Psicólogo. Doutor pela PUC-SP e Pós-doutorado na Universidade Complutense de Madrid. Professor Titular da UFSM.

*** Psicóloga pela UFSM. Mestranda do Programa de Pós-Graduação em Psicologia da UFSM. Bolsista CAPES.

Financiamento: CAPES.

Este artigo de revista Estudos e Pesquisas em Psicologia é licenciado sob uma Licença Creative Commons Atribuição-Não Comercial 3.0 Não Adaptada. 